A budget impact model is a part of the pharmacoeconomic analyses recommended by the AMCP Format for Formulary Submissions, Version 2.0, although a health system costeffectiveness model is preferred. ${ }^{30}$

As with all information examined by P\&T committees charged with making value decisions, the source of the information is relevant and should be disclosed and acknowledged. Weinberg reported no specific funding for his review of $\mathrm{AD}$ and pimecrolimus, but he disclosed the receipt of research funds and compensation for participation in the speakers' bureau for Novartis Pharmaceuticals, manufacturer of pimecrolimus.

Chang and Sung are employees of Novartis Pharmaceuticals, the manufacturer of pimecrolimus. One might expect the assumptions in their budget impact model to be conservative, forecasting a small budget impact associated with pimecrolimus. It is up to P\&T committees for health plans and pharmacy benefit managers (PBMs) to use their own data to formulate the assumptions in the budget impact model presented by Chang and Sung or to create their own budget impact model and projection. Fairman and Motheral earned the JMCP 2003 Award for Excellence for their article that employed actual health plan data to overturn the assumptions used in the early decision-analytic pharmacoeconomic models of costeffective treatments for eradication of Helicobacter pylori. ${ }^{36}$

Health plans are well advised by authors Chang and Sung to determine their own medical visit costs for treatment of $\mathrm{AD}$ and pharmacy costs for topical immunomodulators approved for use in AD. For example, data from a PBM pharmacy claims database show that there has been a much larger increase in expenditures for pimecrolimus than suggested by Chang and Sung. Pimecrolimus was ranked \#134 in drug plan expenditures in 2004 , accounting for $0.16 \%$ of total drug plan spending ${ }^{37}$ Claims data from this PBM data warehouse showed that drug plan spending for pimecrolimus increased by $30 \%$ in 2004 , from $0.12 \%$ of total drug plan spending in 2003. Over the 2-year period from 2002 to 2004, drug plan spending on pimecrolimus increased more than 3 -fold, from $0.05 \%$ of total drug plan expenditures in 2002 (drug expenditure rank \#305) to $0.12 \%$ in 2003 (drug expenditure rank \#163) and $0.16 \%$ in 2004 (drug expenditure rank \#134). ${ }^{38}$ Further examination of these real-world data shows that almost all of the 3-fold increase in the proportion of drug plan expenditures for pimecrolimus over this 2-year period was attributable to utilization. The average actual price per standardized 30-day supply of pimecrolimus was $\$ 127$ in 2002, rising 13\% to $\$ 142$ in 2003 and rising by $9 \%$ to $\$ 155$ in 2004 .

Stated in other terms, the per-member-per-month (PMPM) cost of pimecrolimus was about $\$ 0.01$ in 2002, \$0.03 in 2003, and $\$ 0.05$ in 2004 . These data differ dramatically from that presented by Chang and Sung in the results of their pharmacoeconomic model. Their reported \$0.008 PMPM drug cost for pimecrolimus in 2003 would appear to understate the actual cost experienced in this PBM database by about $75 \%$.

\section{Prescription-Equivalent Over-the-Counter Drugs for Allergy, Heartburn, and Cholesterol Reduction}

The first over-the-counter (OTC) statin in the world was introduced to the market in the United Kingdom in August 2004 as Zocor Heart-Pro. The $10 \mathrm{mg}$ simvastatin was marketed by a joint venture of Merck and Johnson \& Johnson. ${ }^{39}$ Whether or not the U.S. Food and Drug Administration (FDA) permits access to an OTC statin in 2005, it seems likely that a low-dose statin will ultimately be available OTC in the United States at some point. As with all conversions from prescription (Rx) to OTC status, savings can accrue from more than the direct cost of the drug. The largest source of cost savings may be derived from fewer physician office visits. From this perspective, organized medicine in general might be expected to be opposed to Rx to OTC "switches."

For consumers and payers, the savings from $\mathrm{Rx}$ to OTC conversions can be very large. Harris et al. showed in a previous issue of JMCP that a state health plan reduced spending on proton pump inhibitors (PPIs) by at least 50\% through a benefit design change and increase in pharmacy reimbursement that favored OTC omeprazole (Prilosec OTC).$^{40}$ Health plan members saved between $80 \%$ and $90 \%$ in copayments per Rx for OTC omeprazole and $17 \%$ in the average PPI claim. Similar but less dramatic savings for drug plan sponsors and drug plan members could be realized through drug benefit coverage of OTC loratadine in which the OTC version (e.g., Alavert) can be purchased for about $\$ 14$ per 30-day supply, $80 \%$ less than the $\$ 69$ charge for a 30-day supply of either desloratadine (Clarinex) or fexofenadine (Allegra). ${ }^{41}$

In a previous issue of JMCP, Richards, Blumenfield, and Lyon found generally favorable but not universally favorable opinions among pharmacy and medical officers in managed care organizations (MCOs) and pharmacy benefit managers (PBMs) regarding the possible introduction of OTC lovastatin to the U.S. market. ${ }^{42}$ More curious in the findings was the reaction of PBMs and MCOs to the availability of generic lovastatin: no PBMs and only $28 \%$ of MCOs changed the formulary status of the other statins. In anticipation of an OTC statin, no PBM or MCO would cover the OTC statin, and only $50 \%$ of all respondents, including one of 4 PBMs, reported that they would encourage use of the OTC statin. This is befuddling and suggests that health plans in general and PBMs in particular will not realize the cost-savings potential of market introduction of OTCs in their administration of prescription drug benefits.

Additional context for the findings of Richards, Blumenfield, and Lyon can be found in the results of 2 surveys conducted during one week in January 2004. Nearly three 
fourths of 200 family practice physicians and 200 internists believed that new approaches are needed to reach consumers at risk for heart disease who are currently not being treated. (The survey apparently did not ask explicitly if the physicians supported OTC status for statins.) A separate survey of 600 consumers aged 30 years or older found that 33\% were currently being treated for high cholesterol. Not surprisingly, OTC statin was of more interest to persons who were already taking supplements, avoided smoking, engaged in exercise, ate a low-fat diet, or who were trying to lose weight either regularly or occasionally. ${ }^{43}$

Lovastatin is not a second-class drug for the reduction of low-density lipoprotein cholesterol (LDL-C) and triglycerides and increase of high-density lipoprotein cholesterol (HDL-C). In 33,318 patients switched from simvastatin (Zocor) to generic lovastatin, Kaiser Permanente researchers found better clinical outcomes with lovastatin at much lower cost. ${ }^{44}$ These study results were presented by Kaiser researchers, David Campen and Eleanor Levin (chief of cardiology for Kaiser Permanente in northern California), at the Scientific Sessions of the American Heart Association during the week of November 7, 2004. Specifically, the 33,318 patients (45\% women) were switched from simvastatin (average dose $25.6 \mathrm{mg}$ per day), to lovastatin (average dose $51.1 \mathrm{mg}$ per day). In the primary prevention group, average LDL-C fell from 119.4 on simvastatin to 116.6 on lovastatin $(P<0.001)$, and average triglycerides decreased from 171.5 to $169.7 \mathrm{mg} / \mathrm{dL}(P<0.01)$; average HDL-C rose from 50.9 on simvastatin to 53.0 on lovastatin $(P<0.001)$. For the secondary prevention group, LDL-C fell from 101.1 to 99.0 $(P<0.001)$, and triglycerides fell from 170.7 to $169.5 \mathrm{mg} / \mathrm{dl}$ $(P=0.046)$; HDL-C rose from 45.7 to $48.1(P<0.001)$. Elevated transaminase or creatine kinase levels were comparable during simvastatin and lovastatin treatment. The authors concluded that clinical outcomes were the same or better for lovastatin compared with simvastatin in patients switched to lovastatin, representing a large improvement in quality since generic lovastatin is much less expensive than simvastatin. Additional quality improvement from this intervention to switch patients from simvastatin to lovastatin might be derived from a smaller proportion of patients discontinuing statin therapy due to the (copayment) cost since a generic copayment is generally at least $50 \%$ lower than a brand-drug copayment. The authors also observed that the average $51.1 \mathrm{mg}$ per day of lovastatin suggests additional room for dose increases since the maximum approved dose is $80 \mathrm{mg}$ per day.

Now would seem to be a good time for P\&T committees in both health plans and PBMs to anticipate the introduction to the U.S. market of an OTC lovastatin. The FDA advisory panel may consider an application from Merck to sell Mevacor (lovastatin) over the counter at its meeting on January 13 and 14, 2005, and Bristol-Myers Squibb announced in mid-December 2004 that it would seek FDA approval for OTC sale of Pravachol (pravastatin) in anticipation of generic competition in April 2006. ${ }^{45}$ The short-term value (clinical outcome divided by cost) opportunity may not be as large as that possible with coverage of OTC omeprazole, where savings are $50 \%$ or greater, ${ }^{46}$ but the long-term value opportunity could be large and certainly warrants attention by P\&T committees.

Frederic R. Curtiss, PhD, RPh, CEBS Editor-in-Chief fcurtiss@amcp.org

\section{REFERENCES}

1. American Lung Association. Smokers not concerned about developing 4th leading cause of death, yet more than half experience symptoms once a week. Available at: http://www.lungusa.org/site/apps/nl/content2.asp?c=dvLUK9O0E\&b= 34893\&ct=294905\&notoc=1. Accessed December 23, 2004.

2. National Institutes of Health, National Heart, Lung, and Blood Institute. Data Fact Sheet-Chronic Obstructive Pulmonary Disease. National Institutes of Health, National Heart, Lung, and Blood Institute. NIH pub no. 03-5229, March 2003. Available at: http://www.nhlbi.nih.gov/health/public/lung/other/ copd_fact.pdf. Accessed December 23, 2004.

3. Tinkelman D, Nordyke RJ, Isonaka S, et al. The impact of COPD on longterm disability costs. J Manag Care Pharm. 2005;11(1):25-32.

4. Celli BR, Cote CG, Marin JM, et al. The body-mass index, airflow obstruction, dyspnea, and exercise capacity index in chronic obstructive pulmonary disease. New Engl J Med. 2004;350:1005-12.

5. Centers for Medicare and Medicaid Services. Why were CHF, diabetes and COPD selected as threshold conditions? Available at: http://questions.cms.hhs.gov/ cgi-bin/cmshhs.cfg/php/enduser/std_adp.php?p_faqid=2667\&gsearch=Y. Accessed December 23, 2004.

6. Social Security Administration. Annual statistical supplement to the Social Security Bulletin. SSA publication 13-11-11700, July 2004. Available at: http://www.ssa.gov/policy/docs/statcomps/supplement/2003/supplement03.pdf. Accessed December 23, 2004

7. Centers for Medicare and Medicaid Services. Medicare Chronic Care Improvement Program—national sample file of Medicare beneficiaries. Available at: http://www.cms.hhs.gov/medicarereform/ccip/Readme.pdf. Accessed December 23, 2004.

8. Ruchlin HS, Dasbach EJ. An economic overview of chronic obstructive pulmonary disease. Pharmacoeconomics. 2001;19(6):623-42.

9. Parmet S, Lynn C, Glass RM. Chronic obstructive pulmonary disease. JAMA. 2003;290:2362.

10. He J, Vupputuri S, Allen K, et al. Passive smoking and the risk of coronary heart disease - a meta-analysis of epidemiologic studies. New Engl J Med. 1999;340:920-26

11. MacNee W. Guidelines for chornic obstructive pulmonary disease. BMJ 2004;329:361-63

12. National Emphysema Treatment Trial Research Group. Patients at high risk of death after lung-volume-reduction surgery. N Engl J Med. 2001; 345(15):1075-83.

13. NHLBI Health Network eBulletin. Available at: http://hin.nhlbi.nih.gov/ joinhin/news/WorldCOPDDay04.htm. Accessed December 23, 2004.

14. Maher K. Companies are closing doors on job applicants who smoke. Wall Street Journal. December 21, 2004:B6.

15. Man SFP, McAlister FA, McAlister FA, Athonisen NR, Sin DD. Contemporary management of chronic obstructive pulmonary disease. JAMA. 2003;290: 2313-16. 
16. CMS Media Affairs. Medicare will help beneficiaries quit smokingnew proposed coverage for counseling as Medicare shifts focus to prevention. Available at: http://www.os.dhhs.gov/news/press/2004pres/20041223a.html. Accessed December 31, 2004.

17. Geisel J. FSA money can fund smoking cessation: IRS. Bus Insur. June 28, 1999:2.

18. Anonymous. Statins will have "preventive" status under health savings accounts. Green Sheet. August 9, 2004:4.

19. Wyeth-Ayerst Prescription Drug Benefit Cost and Plan Design Survey Report. 2000 ed. Tempe, AZ: Pharmacy Benefit Management Institute; 2000.

20. Aventis Managed Care Digest Series 2004. HMO-PPO/Medicare-Medicaid Digest. Sanofi-Aventis; 2004

21. National Committee for Quality Assurance. The state of health care quality: 2004. Industry trends and analysis. Available at: http://www.ncqa.org/ communications/SOMC/SOHC2004.pdf. Accessed December 26, 2004.

22. Baker T, Fox, BJ, Hasselblad V, for the Guideline Panel. Clinical practice guideline-treating tobacco use and dependence. U.S. Department of Health and Human Services; June 2000. Available at: http://www.surgeongeneral.gov/ tobacco/treating_tobacco_use.pdf. Accessed December 26, 2004

23. Prochazka AV, Kick S, Steinbrunn C, et al. A randomized trial of nortriptyline combined with transdermal nicotine for smoking cessation. Arch Intern Med. 2004;164:2229-33

24. Hughes JR, Shiffman S., Callas P, Zhang J. A meta-analysis of the efficacy of over-the-counter nicotine replacement. Tobacco Control. 2003;12(1):21-27. Available at: http://tc.bmjjournals.com/cgi/content/full/12/1/21?ijkey=5.ko5/ Oz4yut. Accessed December 27, 2004.

25. Sonderskov J, Olsen J, Sabroe S, Meillier L, Overvad K. Nicotine patches in smoking cessation: a randomized trial among over-the-counter customers in Denmark. Am J Epidemiol. 1997;145:309-18.

26. Polito JR. The NRT cessation charade continues. BMJ. (Rapid Responseonline). February 23, 2004.

27. Curry SJ, Grothaus LC, McAfee T, et al. Use and cost-effectiveness of smoking-cessation services under four insurance plans in a health maintenance organization. New Engl J Med. 1998;339(10):673-79.

28. Eddy DM. Evidence-based medicine: What it is, why to use it, and how to incorporate it into decision-making. Formulary. 2002;37:525-30.

29. Ortiz E. Market withdrawal of Vioxx: It is time to rethink the use of COX-2 inhibitors? J Manag Care Pharm. 2004;10(6):551-54.

30. Format for Formulary Submissions. Version 2.0: A Format for Submission of Clinical and Economic Data in Support of Formulary Consideration by Health Care Systems in the United States. Alexandria, VA: AMCP, Foundation for Managed Care Pharmacy; 2002. Available at: http://www.fmcpnet.org/data/resource/ formatv20.pdf. Accessed April 23, 2004.

31. Fisher V. Clinical monograph for drug formulary review—systemic agents for psoriasis and psoriatic arthritis. J Manag Care Pharm. 2005;11(1);33-55.

32. Weinberg J. Formulary review of therapeutic alternatives for atopic dermatitis_focus on pimecrolimus. J Manag Care Pharm. 2005;11(1):56-64.

33. Drug Facts and Comparisons (CliniSphere version 2.0). St. Louis, MO: Wolters Kluwer Health, Inc. 2004. Dermatological agents, immunomodulators, topical, tacrolimus, indications. Accessed December 24, 2004.

34. Drug Facts and Comparisons. (CliniSphere version 2.0). St. Louis, MO: Wolters Kluwer Health, Inc.; 2004. Dermatological agents, immunomodulators, topical, pimecrolimus, indications. Accessed December 24, 2004.

35. Chang J, Sung J. Health plan budget impact analysis for pimecrolimus. J Manag Care Pharm. 2005;11(1);66-73.

36. Fairman KA, Motheral BR. Do decision-analytic models identify costeffective treatments? A retrospective look at helicobacter pylori eradication. J Manag Care Pharm. 2003;9(5):430-40.
37. Data abstracted December 26, 2004, from a national pharmacy benefits manager (PBM) data warehouse representing approximately 500,000 beneficiaries of small employer drug plans for claims with dates of service for calendar year 2004 through November 30, 2004 [proprietary data].

38. Data abstracted December 26, 2004, from a national pharmacy benefits manager (PBM) data warehouse representing approximately 500,000 beneficiaries of small employer drug plans for claims with dates of service for calendar year 2002, beginning January 1, 2002, calendar year 2003, and for calendar year 2004 through November 30, 2004 [proprietary data].

39. Anonymous. Johnson \& Johnson. Wall Street Journal. July 30, 2004:B5.

40. Harris, BN, West DS, Johnson J, et al. Effects on the cost and utilization of proton pump inhibitors from adding over-the-counter omeprazole to drug benefit coverage in a state employee health plan. J Manag Care Pharm. 2004; 10(5);449-55

41. www.drugstore.com. Prices accessed September 18, 2004.

42. Richards MK, Blumenfield S, Lyon R. Managed care market perspectives on the OTC availability of OTC statins. J Manag Care Pharm. 2004;10(6):543-50.

43. Anonymous. National Lipid Association Physician and Consumer Surveys. Available at: http://www.lipid.org/news/1000009.php. Accessed August 3, 2004.

44. Anonymous. Kaiser Permanente research: Generic statin drugs produce similar —or better—results than brand-name drugs—brand-name drugs can cost five times as much. NewsEdge. November 8, 2004. Details derived from the AHA session abstract obtained from one of the authors (CR): Levin E, Cheetham CT, Chan J, Richmond C, Benson VM, Campen D. Successful conversion of 33,318 patients with hypercholesterolemia from a brand-name to a generic cholesterol-lowering drug; November 7, 2004. Abstract 3781.

45. Anonymous. Bristol-Myers seeks over-the-counter Pravachol sales (update 2). December 10, 2004. Available at: http://www.bloomberg.com/apps/news?pid= 10000103\&sid=aC5K4HsGapoQ\&refer=us. Accessed December 26, 2004.

46. Curtiss FR. OTC omeprazole for your heartburn-enormous valuefor-money opportunity. J Manag Care Pharm. 2004;10(5):458-59.

\section{Letters to the Editor}

JMCP welcomes letters that serve to clarify subjects published in previous issues of the Journal or regarding subject matter of interest to managed care pharmacists. Letters in JMCP are not peer reviewed but are subjected to editorial review. When a submitted letter refers to an article published in a previous issue of the Journal, the letter is sent to the authors of the subject article to allow their response to be published with the letter.

Each letter should be signed by no more than 3 authors. Submissions must include your title, affiliation, complete mailing address, telephone number, and e-mail address. Potential bias or conflicts of interest must be disclosed.

Letters should be prepared in a word processing program, preferably Microsoft Word, and submitted electronically at jmcp.msubmit.net. 